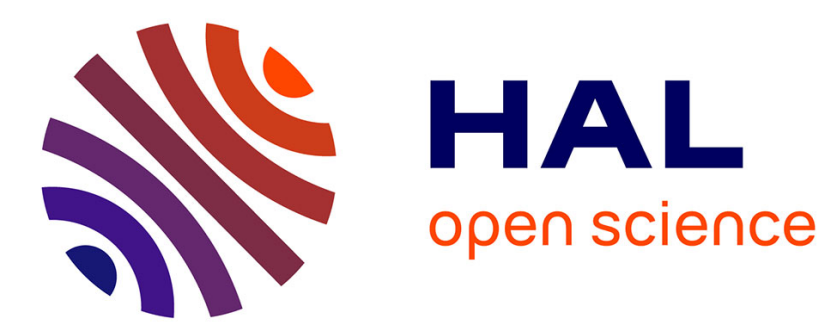

\title{
CORROSION OF GRAIN BOUNDARIES : INITIATION PROCESSES AND TESTING
}

\author{
Luc Beaunier
}

\section{To cite this version:}

Luc Beaunier. CORROSION OF GRAIN BOUNDARIES : INITIATION PROCESSES AND TESTING. Journal de Physique Colloques, 1982, 43 (C6), pp.C6-271-C6-282. 10.1051/jphyscol:1982624 . jpa-00222305

\section{HAL Id: jpa-00222305 https://hal.science/jpa-00222305}

Submitted on 1 Jan 1982

HAL is a multi-disciplinary open access archive for the deposit and dissemination of scientific research documents, whether they are published or not. The documents may come from teaching and research institutions in France or abroad, or from public or private research centers.
L'archive ouverte pluridisciplinaire HAL, est destinée au dépôt et à la diffusion de documents scientifiques de niveau recherche, publiés ou non, émanant des établissements d'enseignement et de recherche français ou étrangers, des laboratoires publics ou privés. 
JOURNAL DE PHYSIQUE

ColZoque C6, supplément au $n^{\circ} 12$, Tome 43, décembre 1982

page $\mathrm{C} 6-271$

\title{
CORROSION OF GRAIN BOUNDARIES : INITIATION PROCESSES AND TESTING
}

\author{
L. Beaunier \\ C.N.R.S. Laboratoire de Physique des Liquides et Electrochimie, Université \\ Pierre et Marie Curie, 4 place Jussieu, 75230 Paris Cedex 05, France
}

\begin{abstract}
Résumê. - Le propos de cette communication est de discuter avec de nombreuses citations les processus qui interviennent dans 1 'initiation de la dissolution préférentielle des joints de grains. Différents paramètres sont présentés : effet structural, propriétés électriques et chimiques, effet électrochimique et autocatalytique. Différents tests sont analysés en vue d'étudier plus spécialement les effets de ségrégation et de structure. Il résulte de cette étude que la composition des joints de grains est le facteur le plus important car il agit sur tous les paramètres précités.
\end{abstract}

Abstract. - The aim of this paper is to discuss with numerous citations the processes which involve the initiation of the preferential dissolution at grain boundaries. Different parameters are considered : structural features, electrical properties, chemical properties, electrochemical and autocatalytic effects. Different tests are reviewed specialy with regard to segregation and structure effects. It is pointed out that the composition of grainboundaries is the most important since it modifies al1 the above-mentionned parameters.

\section{INTRODUCTION}

In many environments as salt water or chemical or nuclear engineering, composition and especially microstructure of metals and alloys are of primary importance. The practical consequences of structure dependent reactions may often lead to cost and catastrophic events e.g. intergranular penetration, pitting corrosion, stress corrosion cracking. Our purpose is to discuss some parameters which concern intergranular corrosion corresponding to a selective dissolution of grain boundaries when they are placed in certain agressive conditions. This process involve aspects of chemistry, metallurgy and electrochemistry.

Firstly, we have to separate exterior corrosion parameters as stress, oxydation, diffusivity of environmental elements (e.g. hydrogen, sulphur atmosphere) and intrinsic parameters of grain boundaries wich determine the reactivity of material to intergranular corrosion susceptibility. Secondly, grain boundaries corrosion has to be separated in two cases :

a - materials with heterogeneous grain boundaries in which precipitation can produce important variations of composition (e.g. impurity solute depletion accompanied with a second phase);

b - water-quenched materials with or no ageing treatment without precipitate. For the latter, the contribution of grain boundaries to attack is associated with their structure, their solute enrichment and higher diffusivity.

Microstructural features appear to influence markedly those corrosion reactions in which localized or preferential corrosion attack occurs. We have to consider a two-step process :

a) - nucleation or initiation stage which is controlled to a large extent by structure sensivity i.e. site nucleation and distribution of attack is determined by metallurgical factors and the nonhomogeneity of the surface often play a practical role in initiating corrosion.

b) - growth and propagation stages of the corrosion process which may be structure sensitive but also influenced by kinetic factors such as film formation, diffusion reactions, passivity or polarization. 


\section{1 - INITIATION STAGE AND PROCESSES}

In considering the role of kinetics and structure on corrosion mechanism, we need to delineate the types of structural features which underlie the heterogenous nature of a metal surface and location to preferential attack. We have to consider :

- growth features : grain boundaries and sub grain boundaries

- deformation features : slip marking, twin band, stacking fault, dislocation arrays

- microstructure : impurities, precipitates, secondary phases resulting from phase transformation and compositional variations.

In fact, it is difficult to unequivocally separate the effects of structure composition and deformation, because distortion of the lattice can be intimately associated with concentration changes e.g. segregation of solute and impurities at grain or phase boundaries.

\section{1 - a) STRUCTURAL FEATURES}

The surfaces are not perfectly flat and uniform but rough and irregular characterized by a terrace ledge structure. We know that the different types of surface sites have different chemical or energetical properties :

- normal site in different close packed plane

- edge of close packed plane

- kink

- point defect : adsorbed atom or vacant lattice sites

- site of intersection of dislocation with crystal surfaces and so grain boundaries It should be easiex to remove atoms from kinks or ledges than from the rest of the surfaces, since atoms at such sites have fewer nearest neighbors and are less strongly bounded than in the close packed plane. Moreover, the surface energy of a crystal is markedly dependant upon crystal orientation.

Numerous papers have discribed the atomic structure of grain boundaries. Different models are proposed : amorphous or as Iiquid structure, geometrical, energetical. Grain boundaries are regions of atomic mismatch between two adjoining grains. The extent of the mismatch region may range from a few atomic layers in metal to several hundred angströms in oxide. Such an imperfect region would be anticipated to have a higher energy state and a greater chemical reactivity. The sites of intersection of dislocation or grain boundary planes appear to be most relevant to corrosion reactions because there, more important perturbation exist near atoms (number of nearest neighbour, bound strength) and then we have here the presence of localized strain energy which can induce strong composition effects. These defects are active sites of initiation for anodic dissolution or electrocrystallization. Numerous papers discuss the energy misorientation relationship of grain boundaries [ 1 , 2,3 and this issue] and some others discuss the surface dissolution in terms of imperfections or defects $[4,5,6]$. In the case of grain boundary dissolution we have found only one study which discuss this phenomenon in term of physical active sites with reference to the structure and the number of neighbour $[7,8]$; this model is a geometric description of grain boundaries in stainless steel bicrystals $<100>$ Tilt : the studies with misorientation and asymetric parameters describe grain boundaries as a succession of geometrical unit were atoms are considered with their coordination (number of first neighbour) as indicated on the figure 1 . These atoms are considered corresponding to the active sites leading to a rapid dissolution. Thus a parameter D/C gives an estimation of the importance of the zones of defect (D) compared with the zones of good atomic fit [cohesion (C)]. Figure 2 shows the evaluation of the relation $D / C$ vs. the misorientation. If this figure is compared with the experimental results -figure 3- a good correlation can be remarked in parricular for the special coincidence grain boundaries $\theta=37^{\circ}(130), \theta=53^{\circ}(120)$ and $\theta=67^{\circ}(230)$. This geometrical description agrees with description of grain boundaries in different compact polyhedral groups of atoms [9].

If it is extremely difficult to etch a pit in higly pure metals at dislocation, such a process occurs at grain boundaries with or not dislocation. In this case, it seems that we can introduce the atomic volume parameter. As a mater of fact this parameter has an important effect for grain boundary dissolution [10, 11]. With electrochemical experiments it has been pointed out that the atomic volume of grain boundary influence greatly susceptibility to corrosion. It was demonstrated that with this technics it is possible to determine this parameter with sucess on different ageing specimensof embrittled Ni-S alloys. 


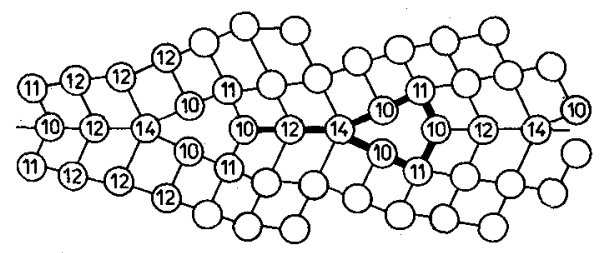

$$
\text { (140) } \theta=28.07^{\circ}
$$

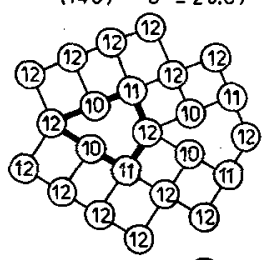

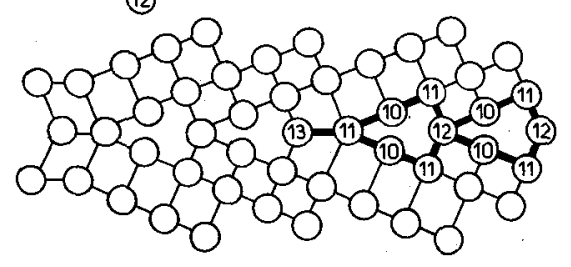

(350) $\theta=61.92^{\circ}$
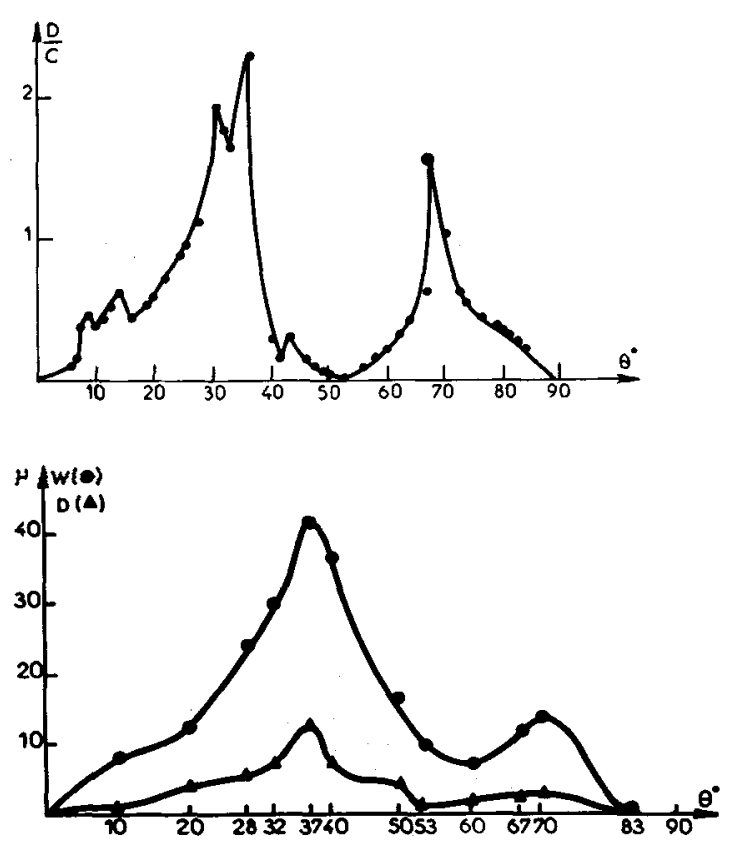

Fig. 1.

Coordination number of atoms of some structural units.

Fig. 2

Evolution of the D/C parameter with angle $\theta^{\circ}$.

Fig. 3.

Dependence of the experimental width and depth of intergranular groove with misorientation $\left(0-90^{\circ}\right)$. 


\section{1 - b) ELECTRICAL PROPERTIES}

Few authors have studied the electrical properties of grain boundary but never in relation with the dissolution process. It was pointed out that the grain boundaries have an effect on the resistivity of metals. This phenomenon is interpreted by a model of electronic barrier plane. Thus the resistivity of the grain boundaries is different from those of the matrix and induces electronic accident on the surface [12]. Grain boundary electrical scattering is due essentially to the defects wich contribute to the grain boundary and the effect is due to the dislocation core rather than the long range elastic strain field [13]. This phenomenon and the transport process have an important effect in grain boundary migration [14]. In thermodynamics of metal surfaces extended to the particular case of a metal electrode surface the stress is directly affected by variations in the charge density of surface [15]. An important parameter of the metal solution interphase which has a direct significance in electrode kinetics is the potential of zero charge (z.c.p.) which appears to be related to a principal surface state property of metals, namely workfunction [16]. The workfunction seems to be directly proportional to the rate of dissolution. We measure z.c.p. by double layer capacity by electrochemical impedance in function of superficial stress. All these results can be transposed at the surface modification at the emergence of grain boundaries but unfortunately no localized study can be actually experimented in corrosion process at the emergence of grain boundaries.

Some studies have pointed out that in alloys the dissolution rate is modified not only by chemical effect but also by electron configuration. Potentiostatic anodic polarization data show that a transition from active to passive state is observed for $\mathrm{Ni}-\mathrm{Cu}$ and $\mathrm{Ni}-\mathrm{Cu}-\mathrm{Zn}$ alloys only when the $3 \mathrm{~d}$ band of energy level in the alloys is unfilled. At and above a critical alloy composition, electrons from $\mathrm{Cu}$ or $\mathrm{Zn}$ completely fill the $\mathrm{d}$ band and the passive state disappears $[17,18]$. This phenomenon observed in the case of surface dissolution must be taken in consideration in the case of various elements segregated at grain boundaries as far Ni-Si alloys [7]. It is shown that in the case of low angle grain boundaries the activity increases with an increase of the angle misorientation. This phenomenon is connected with deformation of the surface layer of the lattice and after with segregation of impurities by the formation of a one dimensional zone of electronic states [59]. All these effects modify the reactivity at grain boundaries.

\section{1 - c) CHEMICAL PROPERTIES}

It is well known that the difference of thermodynamical properties of metals gives rise to strong effects on corrosion of surface. The same process is true for grain boundary. For example, a study has pointed out that in nickel base alloys the increase of chromium or nickel content increases sharply the intergranular corrosion susceptibility of the alloy with a more pronounced effect with chromium [19]. The reactivity of nickel is enhanced by carbon, sulphur, selenium, tellurium. The electrochemical reactivity denotes an increase with this element and significant inhibition of passivity [20]. The same phenomenon occurs at homogeneous grain boundaries $[10,21,22,23]$. But region adjacent to grain boundaries may be chemically different from the bulk. This because the large elastic strains in the vicinity attrack atoms having a larger or smaller atomic diameter that the host lattice. This attraction is equivalent to that of a dislocation. Grain boundary tension is function of the composition [24]

d $\sigma=-\sum \Gamma_{i} d \mu_{i}$
$\mu_{i}$ chemical potential of $I^{\text {th }}$ component
$\Gamma_{i}$ excess amount. of $I^{\text {th }}$ component per unit of grain boundary area.

Here, we have to consider two very different cases in the thermodynamical and chemical approach :

- major element of the bulk can have a different reactivity of dissolution when they are at grain boundaries and also can segregate in the plane of these defect [19]

- minor element can be attracted to or repulsed from the grain boundary [22, 51].

Several papers have described the energetics of grain boundary segregation in

the case of intergranular fracture. They have pointed out a low cohesive energy in the segregated grain boundary which interprets some phenomenon of fragility because 
segregate bonds give rise to a weak interface. 1.e. effect of sulfur, phosphorus, carbon, boron in the case of iron and nickel $[25,26,27,28,29]$. In all these cases we have not only a chemical effect but also a strong influence of the decohesion of the interface on the grain boundary corrosion. In addition, the corrosion process can be emphasized by selective dissolution of surface and/or grain boundaries [28].

An other chemical effect is the autocatalytic effect. For example, grain boundary corrosion of aluminum is catalysed preferentially by small amounts

of the ions $\mathrm{Cu}, \mathrm{Ag}$ or $\mathrm{Ni}$ [30]. In the case of $\mathrm{Al}-\mathrm{Cu}$ alloys intergranular corrosion existswhen we have a solute depleted zone at the grain boundaries when anions contained in the solution are capable to break down the passivity of Al. The breakdown potential of the depleted zone must be lower than that of the grains. Corrosion potential of the alloy must be between breakdown potentials of grains and grain boundaries [31]. In all these cases we have to note that the chemical effect is more important that the intrinsic structure effect of the grain boundaries.

\section{1 - d) ELECTROCHEMICAL PROPERTIES}

From a variety of experimental studies, it was concluded that if impurity is present at a grain boundary, a zone of appreciable width along the boundary may possess electrochemical properties different from those of the grains [32]. KC1 on zinc produce geometrical pits in the grains, whereas on zinc of lower purity these pits are absent but there was attack upon the grain boundaries [33]. Thus impurity segregation of the equilibrium and/or non equilibrium types promotes increased attack in the grain boundaries. If segregate is more noble than the bulk, grain boundary is cathodic and we have attack of the vicinity which is anodic i.e. sensibilizated stainless steels, $\mathrm{Al}-\mathrm{Cu}$ alloys. In opposit,grain boundaries are anodic in Al-Mg alloys. Thus, some authors consider that a grain boundary is an anode and that the corrosion susceptibility arises not in a driving force as grain boundary energy difference but in the polarization [34, 35]. Potential measurements have shown that groove at grain boundaries occurs and are anodic in some environment. Some other authors have studied the necessary overvoltage for electrocrystallization or dissolution at emergence of dislocation $[36,37,38]$. A cluster of silver atoms grows for an overvoltage of $10 \mathrm{mV}$ and an edge pit for $2,5 \mathrm{mV}$. But at emergence of dislocation the overvoltage is lower near $1 \mathrm{mV}$. Then the dissolution is easier at surface defect.

As we have seen earlier, the existence of grain boundaries modifies the energy and thermodynamic properties of atoms at the emergence on the surface. Thus is seems possible to have also at grain boundaries an overvoltage as far crystallographic defects. More precisely for a dissolution reaction we have

$$
\Delta G=\Sigma n_{i} \mu_{i} \text { (final state) }-\sum n_{i} \mu_{i} \text { (initial state) }
$$

where $\mu_{i}$ is the chemical potential of species. And if $v_{i}$ is the electrical potential, the electrical energy is $z_{i} F V_{i} J / m o 1$. Then we define the electrochemical potential.

$$
\overline{\mu_{i}}=\mu_{i}+z_{i} F v_{i}
$$

The change in electrochemical energy is

$$
\Delta \bar{G}=\Delta G+\sum n_{i} z_{i} F V_{i} \text { (final state) }-\sum n_{i} z_{i} F v_{i} \text { (initial state) }
$$

The electrical work is $\mathrm{z} F \Delta \mathrm{V}$ where $\Delta \mathrm{V}$ is the single potential or the potential drop across the double layer. It means that the electrical work balances the chemical free energy and we are at the equilibrium potential Veq. But if a defect is present this value raises from a value $\Delta V$ named the overpotential. The electrochemical change due to this phenomenon is

$$
\Delta \mathbf{G}=-z \mathrm{~F} \quad \Delta \mathrm{V}
$$

This expression is valid only for general dissolution but has been applied wich the hypothesis that $\Delta G$ is the energy of grain boundaries [39] : in the case of nickel grain boundary having a width of three atomic parameter and an energy of $850 \mathrm{ergs} / \mathrm{cm}^{2}$ it was calculated that $\Delta \mathrm{G}=1,68 \mathrm{Kcal} / \mathrm{mol}$ which corresponds to an overpotential of $36,4 \mathrm{~m} / \mathrm{V}$. It seems more realistic to consider the energy of atoms at emergence of grain boundaries rather than grain boundary energy. Then, in first approximation they have an energy $\Delta \mathrm{G}$. Atoms at grain boundaries have a higher energy because they are foreign solute atoms or because they have more or less coordinate bond than in the bulk. The excess of chemical energy is $\Delta \mu \mathrm{g} \cdot \mathrm{b}$ and $\Delta \mathrm{G}=-\mathrm{zF} \Delta \mathrm{V}-\Delta \mu \mathrm{g} \cdot \mathrm{b}$ 
Thus, we have a second term in the expression of the chemical free energy. WEST [40] calculates the potential difference introduced by groove at emergence of grain boundary considering an extra lattice energy spread over a band of atoms some five lattice spacings wide. A groove is formed. If one mole corresponds to a volume $\mathrm{Na}^{3}$ (N Avogadro's number), a groove of 5 a produces two surfaces each $\mathrm{N}^{2} / 5$ in area. Writting $\gamma$ for the specific interfacial energy

$$
\Delta \mathrm{G}=-z \mathrm{~F} \Delta \mathrm{V}-\Delta \mu \mathrm{g} \cdot \mathrm{b} \cdot+\frac{2}{5} \mathrm{~L} \mathrm{a}^{2} \gamma
$$

The value of $\Delta \mu \mathrm{g} \cdot \mathrm{b}$. in an actived grain boundary $\Delta^{*} \mu \mathrm{g} \cdot \mathrm{b}$. is difficult to estimate but is here given as the sum of $\Delta \mu \mathrm{g} \cdot \mathrm{b}$. and an elastic energy term amounting to $10^{-7}$ times the elastic modulus. Then for nickel $\Delta \mu \mathrm{g} . \mathrm{b} .=5,18 \mathrm{~kJ} / \mathrm{mol}, \Delta * \mu \mathrm{g} . \mathrm{b} .=57,7 \mathrm{~kJ} / \mathrm{mol}$ $\gamma=1,28 \mathrm{~J} / \mathrm{m}^{2}$ and $\Delta \mathrm{G}=38 \mathrm{~kJ} / \mathrm{mol}=0,200 \mathrm{~V}$ [40]. These calculations seem to be employed only when the dissolution occurs near the equilibrium electrochemical potential. But when attack occurs in other region of potential, the process is controlled by film growth and it is more realistic to consider a kinetic mecanism. Here, the potential is the same at grain boundaries and on the surface and is a consequence of oxydo-reduction reaction [39]. The current dissolution is

$$
I=I_{0} e^{b V} \text { with preexponential term } I_{0}=K e^{-E / R T} \text { where } E \text { is activation }
$$
energy and $K$ proportional to the number of active sites. We have proposed [41] for general dissolution $I=Z F k \frac{K T}{h} \exp -\frac{E f}{R T} \exp -\frac{E d}{R T} \operatorname{exp~} b\left(V-V_{0}\right)$ $\mathrm{k}$ kinetic constant, $\mathrm{K}$ Boltzman constant, $\mathrm{h}$ Planck constant, Ef formation energy of active sites, Ed dissolution energy, $V-V_{0}$ overpotential. A similar expression is developed at grain boundaries. With a original interpretation model of groove feature at grain boundaries, we have the relation

$$
I g \cdot b \cdot=I_{s}\left(\sin \frac{\alpha_{0}}{2}\right)^{-1}
$$

$I_{s}$ is surface current and $\alpha_{0}$ the angle of the groove at equilibrium and we have the excess energy of active sites $\sin \frac{\alpha_{o}}{2}=\exp \frac{\Delta g \cdot b \cdot(E f)}{R T}$

The kinetic interpretations have permitted to formulate an expression of grain boundary current in which intervene two factors peculiar to the susceptibility of grain boundary corrosion

$$
I_{\text {g.b. }}=I_{\text {g.b.o }}+\left(I / \sin \frac{\alpha_{o}}{2} I_{s}\right.
$$

$I_{\text {g.b.o }}$ connected to the concentration of active sites at grain boundary and to $\alpha_{0} ; \alpha_{0}$ itself, depending upon the difference of the energy of formation of active sites. Then the surplus of grain boundary current dissolution is

$$
I_{g . b . o}=C^{*} \text { g.b. } I_{o s} \exp -\frac{\Delta \dot{g} \cdot b . .(E f)}{R T}
$$

where $C^{*} \mathrm{~g} \cdot \mathrm{b}$. is a surplus of active sites [41].

The significance of the energy of activation for the dissolution reaction of surfaces in acid is discussed in $[42,43,44,61]$.

We have to note that high grain boundary energy gives only some millivolt as difference potential but on the other hand this difference can be very important if segregate species are present. An other fact is that under thermodynamic equilibrium conditions, no potential difference exists between different crystal orientations, no crystal orientation is thermodycally more stable than any other. Under non equilibrium conditions different crystals faces of a metal indeed do corrode at different rates, although, the differences are usually too small to be of practical significance [45].

\section{2 - PROPAGATION STAGE}

After the initiation stage, a propagation stage takesplace and a groove is developed at grain boundaries. This process is very sensitive to the all earlier discribed phenomena but also influenced by kinetic factors such as film formation, diffusion reactions, passivity or polarization.

As we have seen earlier, when we study anodic dissolution of binary alloys, heterogeneous alloys can be treated as simple galvanic couples but for homogeneous 
alloys often they are subject to a modification of surface enrichment. (i.e. tinzinc, cadmium-zinc, iron-chromium, titanium-chromium, iron-titanium [60]). This phenomenon can be more rapid at grain boundary and then we have a modification of the corrosion rate at the emergence on the surface.

An other fact is that when a passivating film exists the film formed is less perfect over the boundary zone. Its strength may depend drasticaly on the nature of segregated species at grain boundaries. In this case, impurities might locally increase the electronic conductivity of the oxide then dissolution is easier. But even for unsegregated grain boundaries, activity occurs through the oxide layer. In the case of iron, regions of intense uptake of the anion, corresponding to sites of incipient breakdown of the oxide at which local anodes are produced, have been found to be more extensive at position overlying grain boundaries in the metal than elsewhere [62].

Cold work can induced also important modification in the dissolution process of grain boundaries because many dislocations and defects are present in the matrix and in the grain boundaries which can interact with impurity. In Ni-Si alloy, effect of cold-work inducesa higher reactivity of grain boundaries and segregation effect is modified [70]. In an other way hydrogen embrittlement reduces the corrosion process [11].

\section{3 - TESTING OF GRAIN BOUNDARIES CORROSION}

Studies of grain boundary corrosion has been to be divided in two ways : first1y, materials are tested in their own environment for the understanding of their susceptibility; secondly with a fundamental consideration, specific and general test are developed which give better correlation with intrinsic properties. But each new alloy and new environment must be investigated specifically and often empirically. It must be noted that conventional specimens give macroscopic information and often do not reveal the fine details of the causative and the mechanistic features of the corrosion processes.

Most of the studies are made with polycrystalline materials. But recently, bicrystals with caracterized grain boundaries are developed. This bicrystal has been elaborated particularly for studies on stainless steels $[46,47,48]$, aluminum [49, $50,51]$ and copper, silver, nickel [52]. At last, morphological results on the intergranular corrosion are more precise with the use of scanning electron microscope and transmission electron microscope for the growth and initiation stage of the corrosion.

\section{3 - a) CHEMICAL ATTACK}

The selective etching of grain boundaries by specific metallographical reagents is well known and described in numerous papers or metallographic books [i.e. 53]. For example : with picric acid solution we can differentiate segregated and not segregated steel $2 \%$ Mn [54]. Segregation of sulphur in high purity iron can be revealed by chemical etching in a oxalic acid hydrogen peroxide aqueous solution [55]. Etch of grain boundaries of nickel with $\mathrm{HNO}_{3}, \mathrm{CH}_{3} \mathrm{COOH}, \mathrm{CH}_{3} \mathrm{CO}-\mathrm{CH}_{3}$ (10 cc each) and of aluminum in $10 \% \mathrm{HCl}$ [49,51]. And for stainless steels ${ }^{3}[56]$, in particular for sensitized stainless steels, the corrosion is developed in $\mathrm{HNO}_{3}+\mathrm{Cr}^{\mathrm{VI}}+$ solution which corresponds to the transpassive region of other electrochemical tests. But this solution seems to be not specific to $\mathrm{Cr}$ depleted zones because in the transpassive region the corrosion rate decreases with decreasing $\mathrm{Cr}$ content in opposition to the well known behaviour in the active and passive region. Many authors now agree that preferential attack to the grain boundaries in this solution is essentially indicative of intergranular segregation $[57,58]$.

\section{3 - b) ELECTROCHEMICAL ATTACK}

The understanding of the role of microstructural features requires the characterization of the specific metallurgical heterogeneities wich provide the local anodes and cathodes and local cell action and more importantly the knowledge analysis of polarization and electrochemical behaviour of such heterogeneities. The electrochemical theory of corrosion emphasizes the importance of electrode potential and polarization phenomena for a proper interpretation of what is going on at the metal interface during intergranular reactions. In this way potentiostatic, potentiokinetic and impedance techniques were developed and have take advantage of recentipro- 
gress [63]. When chemical test are based on the morphological observation and weight loss measurements of specimens, electrochemical tests give many information as potential, current, quantity of electricity wich are rigorously controlled.

The majority of the intergranular tests which have been made, permits only the detection of precipitations and chromium depleted areas. These methods are well described in the literature for light element [64] and nicke1-chromium steel alloys $[53,65,66]$. These methods are sensitive to a great range of precipitation and most are based on the electrochemical potentiokinetic reactivation (cycle in a potential region). The surface of the diagram is proportional to the dissolution area and is correlated with weight loss measures [71]. But these results are only macroscopic and cannot informe on the intrinsic and local properties of grain boundaries. Hence, they are not applicable to the intrinsic intergranular corrosion which corresponds to homogeneous water-quenched materials without precipitation.

For the latter, it has been observed the formation of groove at the emergence of grain boundaries of stainless steels (figure 4) [67], and that a variety of a1loys exhibited preferential intergranular corrosion when the potential was chosen in the initial rise of the transpassive peak [68]. The evaluation of the attack is made by width, depth, and angle measure of the grooves. Corrosion mechanisms are not well known and complex. It is often impossible to correlate intergranular corrosion susceptibility with intergranular structure and energy. Based on the assumption that the importance of transpassive electrochemical intergranular corrosion is proportional to the decohesion [8] a kinetical model has been developed [21, 41]. To explain the formation of the grooves it was pointed out the existence of a dissolution current of the grain boundaries, $I_{g . b}$, more important than that of the surface, $I_{s}$ (figure 5). Then, these two currents establish an equilibrium directly connected with the dihedral angle of the groove.

$$
I_{g \cdot b .}=I_{s}\left(\sin \frac{\alpha}{2}\right)^{-1}
$$
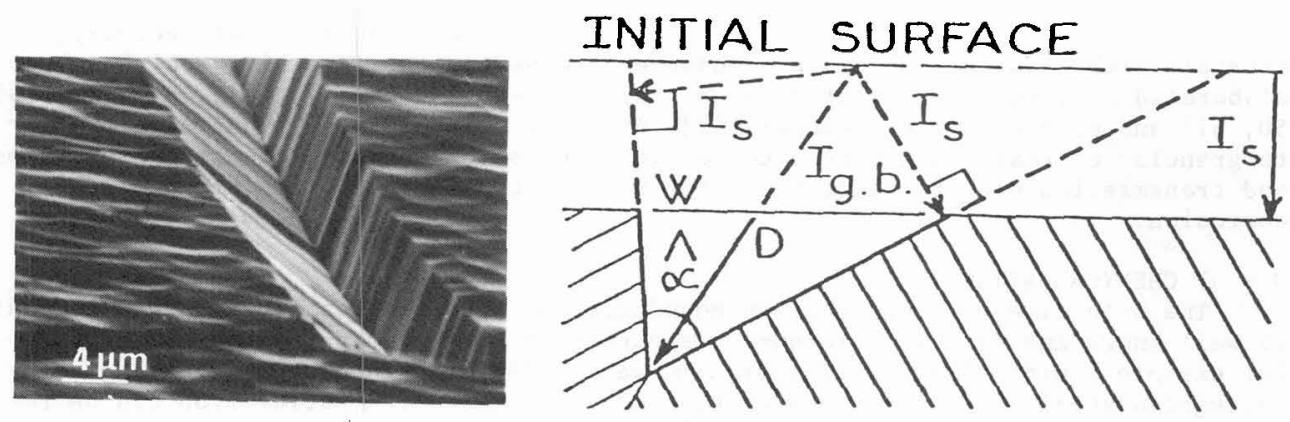

Fig. 4.

Intergranular attack of nicke 1 IM. $\mathrm{H}_{2} \mathrm{SO}_{4}-25^{\circ} \mathrm{C}-20 \mathrm{C} \mathrm{cm}^{-2}$.

Fig. 5 .

Model of dissolution at grain boundary.

A complete study is developed on the evolution of the angle groove $\alpha$, width $W$ and depth $D$ with potential and current dissolution. In particular, greater is the susceptibility to the intergranular corrosion, narrower is the angle groove. An other observation is that the angle increase sharp1y with the current $I_{\text {s }}$ and ascends asymptotically towards a limit value $\alpha_{o}$. This latter indicates the susceptibility of the alloy to intergranular corrosion and may be related to the density of active sites as we have seen earlier $(1-d$ equation $6 \rightarrow 10)$. Then it is possible to determine the energy of formation of active sites (see $1-d$ ). This test is used for all iron-nickel - chromium alloys [41]. An electrochemical investigation of grain boundary in silver has been made with anodic potentiostatic pulse in the vicinity of the equilibrium potential. Here the intergranulax attack occurs by ohmically controlled direct transport. The authors try to correlate the shape of the groove to the energy of active sites at grain boundaries [69]. 
In several cases the electrochemical study permits a quantitative approach of the intergranular corrosion. For example the presence of sulphur at nickel grain boundaries influences dramaticaly the grooves of the attack. It was pointed out that this element alters the mean atomic volume at grain boundaries even at lowest value in the matrix (5 weight p.p.m.). Then with the electrochemical deduced value of the atomic volume at the grain boundary it was deduced the sulphur amount segregated [10].

\section{CONCLUSION}

Numerous examples of intergranular corrosion can be found in the literature where the effects of structure, composition and mechanical stress of grain boundaries are discussed. Our purpose here was to present some reflexions on the initiation stage of intergranular corrosion and on the intrinsic reactivity of grain boundaries when they are placed in corrosion environment.

It is evident that microstructure may or may not be dependent upon particular environments. But when localized dissolution occurs, we have demonstrated that processes are always caused by the heterogeneous character of grain boundaries. At grain boundaries, atom bonds are weaker and different from those of the matrix because atoms are placed in special structural unit polyhedra and they have a different coordination number than the matrix atoms which involve modification of the atomic volume. Also it results special electronic properties at the emergence of grain boundaries.

These processes are intensified as a consequence of the composition of grain boundaries.

Grain boundaries reactivity depends of the composition of the alloy. But the most important remark is that the corrosion penetration seems to be observed on $1 \mathrm{y}$ when impurities are segregated in the grain boundaries. A very low corrosion rate due to the structure effect of grain boundaries is measured for high purity materials. Thus the segregation effect is the major process of the intergranular corrosion even for the lowest concentration. Hence chemical and electronic structure and cohesive energy are modified. To minimize corrosion rate, structure control of specimens can be employed by homogeneization or ageing temperature treatments.

Electrochemical tests are the best to determine and quantify the intergranular sensibility to corrosion and to know in what metallurgical state is the specimen. They permit the analysis of the three important factors which play an important role in the intrinsic susceptibility of grain boundaries to corrosion :

- the effect of major elements of the alloy and the effect of impurities.

- the effect of intergranular segregation.

- the influence of the structure of grain boundaries.

The electrochemical tests are the most sensitive to intrinsic and extrinsic properties of grain boundaries since the initiation and growth stages of intergranular corrosion can be described in term of kinetic dissolution. The description of the emergence of grain boundaries in terms of active sites permits to introduce the surplus of activation energy which is proportional to the intrinsic energy of the structure. Furthermore, coordination of atoms related to cristallographic structure explains their susceptibility to corrosion.

Improvement of our knowledges on the intergranular corrosion requires to perfect the theoritical model of the atomic structure at grain boundaries and its relation with the surface and environment and also general and localized analysis of surface and localized electrochemical measures. 


\section{Références}

[ 1] Colloque CNRS "Les joints intergranulaires", St Etienne, France J. Physique Co11oque C4, sup1. $\mathrm{n}^{\circ} 1036$ (1975) 456.

[ 2] Metal. Soc. of AIME "The nature and behaviour of grain boundaries" Edit. Hsun Hu, Plenum Press (1972) 435.

[ 3] Proceedings of the Int. Conf. on the structure and properties of grain bounda ries and interfaces, Surface Sci. 31 (1972) 622 .

[ 4] BOCKRIS J.0'M., SUBRAMAYAN P.K., Corrosion Sci. 10 (1970) 435.

[ 5] HOAR T.P., Corrosion Sci. 7 (1967) 341.

[ 6] VERMILYEA D.A., J. Electrochem. Soc. 115 $\mathrm{n}^{\circ} 2$ (1968) 162.

[ 7] BEAUNIER L., Thesis of Doctorat d'Etat, Université Paris VI (1979).

[ 8] BEAUNIER L., FROMENT M., VIGNAUD C., J. Electroanal. Chem. 119 (1981) 125.

[ 9] ASHBY M.F., SPAepen F., Williams F., Acta Met. 26 (1978) 1647.

[10] BEAUNiER L., CHEFi C., LARERE A., Vignaud C., J. Microsc. Spectrosc. Electron. I (1982) 171 .

[11] CHEFI C., Doctorat III cycle, Université Paris VI (1982).

[12] PICHARD C.R., TELLIER C.R., TOSSER A.J., Le Vide, Les couches minces 208 (1981) 619 .

[13] BROWN R.A., J. Physique F. : Metal-Phys. $7 \mathrm{n}^{\circ} 8$ (1977) 1477.

[14] HAESSNER F., J. de Physique, colloque C4, supl. $\mathrm{n}^{\circ} 10 \underline{36}$ (1975) 345.

[15] ERB V., GLeItER H., SCWITZ GEBEL G., Acta Meta11. 30 (1982) 1377.

[16] BOCKRIS J.O'M., ARGADE S.D., J. Chem. Phys. 49 (1968) 5133.

[17] MANSFELD F., UHLIG H.H., J. of Electrochem. Soc. $115 \mathrm{n}^{\circ} 9$ (1968) 900.

[18] MANSFELD F., UHLIG H.H., Corrosion Sci. $2 \mathrm{n}^{\circ} 6$ (1969) 377.

[19] BEAUNIER L., FROMENT M., LEPOUTRE D., VIGNAUD C., Metaux Corrosion Industrie L11 $n^{\circ} 625$ (1977) 283.

[20] DIBARI G.A., PETROCELLI J.V., J. of Electrochem. Soc. $112 \mathrm{n}^{\circ} 1$ (1965) 99.

[21] AUST K.T., IWAD 0., Segregation and corrosion at grain boundaries Evans International Conference on localized corrosion, Corrosion NACE (1971) 62-77.

[22] BEAUNIER L., FROMENT M., C.R. Acad. Sci. C 279 (1974) 91.

[23] BEAUNIER L., CHEFI C., FROMENT M., VIGNAUd C., LARERE A., Rev. de Métallurgie M.E.S. 9 (1981) 417 .

[24] STEIN D.F., JOHNSON W.C., WHITE C.L., Canad. Metal. Quarterly 13 (1974) 79.

[25] STARK J.P., MARCUS H.L., Metal Trans.8A BA (1977) 1423.

[26] HONUROS E.D., Metal Science Journal 6 (1972) 110. 
[27] MESSMER R.P., BRIANT C.L., Acta Metal. 30 (1982) 457.

[28] MACHLIN E.S., Scripta Meta1. 15 (1981) 413.

[29] SEAH M.P., Acta Metal. 28 (1980) 955.

[30] METZGER M., ARORA O.P., Trans AIME 227 (1963) 1305.

[31] GALVELE J.R., DE MICHELI S.M., Corrosion Science 10 (1970) 795.

[32] EVANS U.R., The corrosion and oxidation of metals Edward Arnold, London (1967).

[33] Bengough D., LEe A.R., WORMWELl F., Proc. Roy. Soc. A131 (1931) 494.

[34] ARORA O.P., METZGER M., Trans. TMS AIME 236 (1966) 1205.

[35] STREICHER M.A., J. Electrochem. Soc. 106 (1959) 161.

[36] ENGELL H.J., STEEN A., ROTHENBACHER P., Proceedings of the 6th int. Congress of Meta1. Corrosion Sidney (1975) Al.

[37] KAISCHEV R. BUDEVSKI E., Contemp. Phys. 8 (1967) 489.

[38] SCHAARWÄCHTER W., Phys. Stat. Sol. 12 (1965) 375 and 865.

[39] FLIS J., J. Br. Corros. Int. 3 (1968) 182.

[40] WEST J.M. "Basic corrosion and oxidation" Ellis horwood publisher England (1980) 72 .

[41] BEAUNIER L., FROMENT M., VIGNAUD C., Electrochimica Acta 25 (1980) 1239.

[42] VETTER K.J., Elektrochemische Kinetik Springer Berlin (1961) 120.

[43] ARNOLD K., VETTER K.J., Z. Electrochem. 64 (1960) 407.

[44] BOCKRIS J.0'M., Modern aspects of Electrochemistry Academic Press, New York (1954).

[45] JENKINS L.H., BERTOCCI U., J. Electrochem. Soc. 112, $\underline{5}$ (1965) 517.

[46] LEGGETT J.R., PAXTON H.W., Corrosion Science 2 (1962) 217.

[47] ASSASSA W., BEAUNIER L., DESESTRET A., FROMENT M., GUIRALDENQ P., Scripta Met. $\underline{8}$ (1974) 533 .

[48] MONNIER A., PINARD-LEGRY G., Proceedings of the 5th European Congress of Corrosion (1973) 245.

[49] ARORA O.P., METZGER M., Trans. T.M.S. AIME 236 (1966) 1205.

[50] HASSON G., BOOS J.Y., HERBEUVAL I., BISCONDI M., GOUX C., SurE. Sci. 31 (1972) 115.

[51] FROMENT M., VIGNAUD C., Métaux, Corrosion, Industries $n^{\circ} 581$ (1974) 1 et $n^{\circ} 582$ (1974) 67.

[52] GUST W., HINTZ M.B., PREDEL B., ROLL U., Acta Met. 28 (1980) 1235.

[53] ASTM "Intergranular corrosion of stainless alloys" Editor R.F. STEIGERWALD Philadelphia (1977). 
[54] KRAHE P.R., GUTMANN M., Metallography $\underline{7}$ (1974) 5.

[55] PICHARD C., Doctorat d'Etat Thesis, Universitê de Paris VI (1976).

[56] LEE J.B., Corrosion NACE $37 n^{\circ} 8$ (1981) 437.

[57] COWAN R.L., TEDMON C.S., Advance in Corrosion Science and Technology 3 (1973) 293. FONTANA R.G., STAEHLE R.W., Plenum Press New York.

[58] BROWN M.H., Corrosion NACE 29 (1973) 384.

[59] MOLOTSKII M.I., Kinetika i Kataliy $15 \mathrm{n}^{\circ} 3$ (1974) 758.

[60] STEIGERWAL R.F., GREENE N.D., J. of Electrochem. Soc. $109 \mathrm{n}^{\circ} 11$ (1962) 1026.

[61] SCHORR M., YAHALOM J., Corrosion Science 12 (1972) 867.

[62] PAGE C.L., MAYNE J.E.o., Br. Corr. J. $10 \mathrm{n}^{\circ} 2$ (1975) 99.

[63] GABRIELLI C., Metaux, Corrosion, Industrie 573 (1973) 71, 574 (1973) 223, 577 (1973) $309, \underline{578}$ (1973) 356.

[64] LIFKA B.W., SPROWLS D.D., ASTM Spec. Tech. Publ. USA 516 (1972) 120.

[65] WILSON F.G., PICKERING F.B., J. Iron Stee1 Inst. 210 (1972) 37.

[66] HENTHORNE M., ASTM Spec. Tech. Publ. USA 516 (1972) 66.

[67] Desestret A., FROMENT M., Mem. Sci. Rev. Metal. LXII n² 2 (1965) 135.

[68] FROMENT M., Int. Coll. on grain boundaries in Metals $J$. Physique colloque C4, $10 \mathrm{n}^{\circ} 10$ supp1. (1975) 371 .

[69] NANEV CHR.N., VLADIKOVA D., Electrochimica Acta 23 (1978) 325.

[70] BEAUNIER L., CHEFI C., FROMENT M., VIGNAUD C., Proceedings of the 8th Internationa1 Congress on Metallic Corrosion, Mainz RFA I (1981) 50.

[71] MignoNe A., BORELlo A., La BARbERA A., Corrosion NACE $38 n^{\circ} 7$ (1982) 390.

\section{DISCUSSION}

F. CABANE-BROUTY : During your Ni-S study, did you have simultaneously some information on what happens on the surface?

L. BEAUNIER : We are actually at the beginning of an experimentation with a ultrahigh pure metal in order to separate the effect of sulphur from those of othersimpurities at the surface. 